\title{
Dosimetry-based treatment for Graves' disease
}

\author{
Steve L. Hyer ${ }^{a}$, Brenda Pratt ${ }^{\mathrm{b}}$, Matthew Gray ${ }^{\mathrm{b}}$, Sarah Chittenden ${ }^{\mathrm{b}}$, Yong Du ${ }^{\mathrm{c}}$, \\ Clive L. Harmer ${ }^{d}$ and Glenn D. Flux ${ }^{b}$
}

Objective The aim of this retrospective study was to assess the long-term outcome of a personalized dosimetry approach in Graves' disease aiming to render patients euthyroid from a planned thyroid absorbed dose of $60 \mathrm{~Gy}$.

Patients and methods A total of 284 patients with Graves' disease were followed prospectively following administration of radioiodine calculated to deliver an absorbed dose of $60 \mathrm{~Gy}$. Patients with cardiac disease were excluded. Outcomes were analysed at yearly intervals for up to 10 years with a median follow-up of $\mathbf{3 7 . 5}$ months.

Results A single radioiodine administration was sufficient to render a patient either euthyroid or hypothyroid in $\mathbf{1 7 5}$ $(62 \%)$ patients, the remainder requiring further radioiodine. The median radioactivity required to deliver $60 \mathrm{~Gy}$ was $77 \mathrm{MBq}$. Less than 2\% patients required 400-600 MBq, the standard activity administered in many centres. In the cohort receiving a single administration, 38,32 and $26 \%$ were euthyroid on no specific thyroid medication at 3, 5 and 10 years, respectively. Larger thyroid volumes were associated with the need for further therapy.

\section{Introduction}

The optimal radioiodine treatment strategy for Graves' disease is controversial as reflected in the differing guidance offered by international guidelines. The American Thyroid Association aims to render patients hypothyroid by administering $370-555 \mathrm{MBq}(10-15 \mathrm{mCi})$ or $5.5 \mathrm{MBq}$ $(150 \mathrm{mCi})$ per gram of thyroid tissue [1]. The Royal College of Physicians (UK) recommends a fixed activity of 400-600 MBq for rapid elimination of hyperthyroidism accepting that a significant proportion of patients will require life-long L-thyroxine with this approach [2]. In contrast, the European Association of Nuclear Medicine recommends administration of an activity of radioiodine calculated to give an absorbed dose of $150 \mathrm{~Gy}$ to the thyroid where the aim is to restore euthyroidism [3].

A fixed activity approach has the advantages of costeffectiveness, efficiency and early eradication of hyperthyroidism thus avoiding its adverse consequences [4-6]. In contrast, an individualized approach on the basis of dosimetry aims to administer the minimum activity of

This is an open access article distributed under the Creative Commons Attribution License 4.0 (CCBY), which permits unrestricted use, distribution, and reproduction in any medium, provided the original work is properly cited.
The presence of nodules on ultrasonography did not adversely affect treatment outcome.

Conclusion A personalized dosimetric approach delayed the long-term onset of hypothyroidism in $26 \%$ of patients. This was achieved using much lower administered activities than currently recommended. Future studies will aim to identify those patients who would benefit most from this approach. Nucl Med Commun 39:486-492 Copyright (c) 2018 The Author(s). Published by Wolters Kluwer Health, Inc.

Nuclear Medicine Communications 2018, 39:486-492

Keywords: benign thyroid disease, dosimetry, Graves' disease, hyperthyroidism, radioiodine

aDepartment of Endocrinology, Epsom and St Helier University Hospitals NHS Trust, ${ }^{b}$ Department of Physics, ' Department of Nuclear Medicine and ${ }^{\mathrm{d}}$ Thyroid Unit, Royal Marsden NHS Foundation Trust, Sutton, UK

Correspondence to Steve L. Hyer, PhD, MD, FRCP, Department of Endocrinology, St Helier Hospital, Wrythe Lane, Carshalton, Surrey SM5 1AA, UK Tel: + 44208296 2563; fax: + 44208296 2731; e-mail: steve.hyer@nhs.net

Received 19 December 2017 Accepted 27 February 2018

radioiodine necessary to render a patient euthyroid for the maximum length of time in accordance with the ionizing radiation regulations, which are guided by the ALARA (as low as reasonably achievable) principle in radiation protection, that is to keep radiation doses 'as low as reasonably achievable' and stipulate that exposures of target volumes must be individually planned [7]. The disadvantage of remaining on antithyroid medication for longer with this approach is offset by the delayed need for L-thyroxine replacement since $\sim 40 \%$ of patients on longterm L-thyroxine are either over-treated or under-treated, and hence at risk of associated morbidities [8].

Following an initial study that demonstrated that an absorbed dose of more than $40 \mathrm{~Gy}$ iodine-131 $\left({ }^{131} \mathrm{I}\right)$ was needed to achieve short-term control of hyperthyroidism in Graves' disease [9], the long-term prospective study presented here was performed to assess the feasibility and effectiveness of an activity administration calculated to deliver $60 \mathrm{~Gy}$ to the thyroid. Treatment outcomes, in terms of hyperthyroidism, hypothyroidism and euthyroidism were investigated with up to 10 years follow-up. In addition, clinical and ${ }^{131} \mathrm{I}$ kinetic parameters that might predict treatment outcome were examined. 


\section{Patients and methods Patients}

Over a 10-year period (1999-2009), 284 patients [216 female, 67 male: mean age of 46.2 years (range: 18.1-81.6 years)] referred to the Thyroid Unit at the Royal Marsden Hospital for ${ }^{131}$ I treatment of Graves' disease participated in this study, which was approved by the Royal Marsden Hospital Research Ethics Committee. Inclusion criteria stipulated clinical and biochemically proven Graves' disease and no previous radioiodine treatment. All patients provided written informed consent after receiving detailed information about radioiodine treatment including printed radiation protection instructions. Patients with multinodular goitre, autonomous thyroid nodules or cardiac complications (heart failure or atrial fibrillation) were excluded from the study. Patients who were unable or unwilling to come up for the additional six visits required for dosimetry underwent standard treatment with a fixed radioactive iodine dose of $75 \mathrm{MBq}$.

The diagnosis of Graves' disease was made according to standard criteria: typical clinical findings and the presence of thyroid-stimulating hormone (TSH) receptor autoantibodies. Those with a diffuse and homogenous pattern on technetium-99m-scintigraphy were classified as typical Graves' disease (227 patients). The remaining 57 patients with nonuniform uptake on scintigraphy or nodular appearance on thyroid ultrasound scanning were classified as Graves' disease in a nodular thyroid. Thyroid volume was determined immediately before a tracer administration of radioiodine. Radioiodine kinetics was determined following tracer and therapy administrations of $\mathrm{Na}^{131} \mathrm{I}$.

The study schedule is shown in Table 1 . Patients were advised to follow a low-iodine diet and to stop antithyroid medication commencing 3 days before radioiodine administration and continuing for 9 and 6 days for tracer and therapy, respectively. Tracer and therapy administrations were 14 days apart. This schedule ensured that patients were euthyroid at the time of ${ }^{131} \mathrm{I}$ treatment,

\section{Table 1 Summary of study schedule}

\begin{tabular}{ll}
\hline Day -3 & Stop antithyroid medication \\
& Start low-iodine diet \\
Day 0 & Ultrasound scan of thyroid \\
& Administration of radioiodine tracer \\
Day 1 & Thyroid uptake measured \\
Day 2 & Thyroid uptake measured \\
Day 6 & Thyroid uptake measured \\
& Resume antithyroid medication \\
& Resume normal diet \\
Day 11 & Stop antithyroid medication \\
& Start low-iodine diet \\
Day 14 & Administration of radioiodine treatment \\
Day 15 & Thyroid uptake measured \\
& Scintillation imaging \\
Day 17 & Resume antithyroid medication \\
& Resume normal diet \\
\hline
\end{tabular}

thus minimizing the risk of thyroid storm. In addition, it allowed tracer and therapy administrations to be given under the same physiological conditions. Those patients with clinical evidence of thyroid eye disease received $0.5 \mathrm{mg} / \mathrm{kg}$ oral prednisolone with the radioiodine at therapy and with the tracer administration to prevent ophthalmopathy worsening.

\section{Measurements \\ Thyroid volume}

Thyroid volume was assessed by ultrasound performed immediately before tracer administration. Thyroid volume was calculated from the formula: $V_{\text {lobe }}=$ length $(\mathrm{cm}) \times$ width $\quad(\mathrm{cm}) \times$ depth $\quad(\mathrm{cm}) \times m \quad($ where $m=0.479)$ taking the maximal linear dimensions of each lobe on a frozen B-scan image [10]. Texture was graded as homogeneous, heterogeneous or nodular.

\section{Radioiodine kinetics}

Following oral administration of a $0.37 \mathrm{MBq} \mathrm{Na}{ }^{131}$ I tracer administration, radioiodine uptake in the thyroid was measured using a sodium iodide detector with diverging collimator. Thyroid uptake was determined by comparison of the count rates from the patient's thyroid and a known activity of ${ }^{131} \mathrm{I}$ in a standard neck phantom. Background counts were measured with a lead shield positioned between the front of the collimator and the patient's neck or phantom. Percentage thyroid uptake was determined at 1,2 and 6 days following the tracer administration:

$$
U=\frac{C R P \times A S \times 100}{C R S \times A P},
$$

where $U(\%)$ is the percentage thyroid uptake, CRP is the patient count rate (cpm), AS is the activity of the standard $(\mathrm{MBq})$, CRS is the count rate of the standard (cpm) and $\mathrm{AP}$ is the activity in the patient (MBq).

For each patient, the maximum recorded thyroid uptake $(U)$ and the uptake at 6 days were used to determine the effective half-life (days). The effective half-life was set to 8 days in cases where it was calculated to be greater than this value.

\section{Dosimetry}

The activity $(A)$ of ${ }^{131}$ I needed to deliver $60 \mathrm{~Gy}$ to the thyroid was calculated from the following equation on the basis of the Medical Internal Radiation Dose schema:

$$
A=\frac{60 \times M}{0.037 \times U \times T},
$$

where 60 is the target thyroid absorbed dose $(\mathrm{Gy}), M$ is the mass of the thyroid $(\mathrm{g}), U$ is the maximum uptake in the thyroid (\%) and $T$ is the effective half-life in the thyroid (days). 
Radioiodine therapy was administered $1-2$ weeks after the tracer study. At $24 \mathrm{~h}$ after therapy administration the thyroid uptake was measured using the same system and setup as for the tracer study. Owing to the high ${ }^{131} \mathrm{I}$ activity present it was necessary to attach a secondary collimator to the diverging collimator to reduce the sensitivity of the system and thus avoid problems resulting from dead-time. The absorbed dose to the thyroid was then calculated using the thyroid volume and effective half-life calculated in the tracer study.

A gamma camera image was also taken at this time to assess heterogeneity of uptake.

Following radioiodine therapy, antithyroid medications were restarted and continued until patients were clinically and biochemically euthyroid. All patients received radiation protection advice regarding contact with children and time off work in line with standard guidelines. Patients were advised to avoid close contact with young children ( $<3$ years) for 7 days and there was no restriction on work with adults unless contact with pregnant women was possible. Patients attended follow-up at regular visits for a minimum of 12 months up to 10 years with a median follow-up of 37.5 months. At each visit thyroid status was evaluated clinically and biochemically and patients were classified as hypothyroid requiring L-thyroxine (elevated TSH with or without low FT4), hyperthyroid requiring antithyroid treatment (elevated FT4 or FT3 and low TSH) or euthyroid on no specific thyroid medication (normal FT4, FT3 and measurable TSH). The requirement for a further administration of ${ }^{131} \mathrm{I}$ was based on clinical assessment. A second administration of ${ }^{131} \mathrm{I}$ was considered an outcome endpoint and any such patients left the study to be followed in the standard endocrine clinic.

\section{Statistical analysis}

Statistical analysis was performed using GraphPad Prism and Bell Laboratories statistical computing package (Graphpad software; San Diego, California, USA), 'R'. Descriptive statistics are provided as mean \pm SD for normally distributed data or as median with $95 \%$ confidence intervals (CIs) and range for non-normally distributed data. Thyroid status was analysed at 6 months, 1, 3, 5 and 10 years. For the purpose of analysis it was assumed that patients who were hypothyroid on L-thyroxine replacement at discharge remained in the same state.

Table 2 Baseline characteristics with univariate analysis

\begin{tabular}{lcc}
\hline Patients $(n)$ & Male : female & Age [median (range)] (years) \\
\hline Graves (227) & $60: 167$ & $44(18-75)$ \\
Graves + nodules (57) & $7: 50$ & $53(21-82)$ \\
All (284) & $67: 217$ & $18-82$ \\
$P$ value & $0.0239^{\mathrm{b}}$ & $0.0001^{\mathrm{a}}$ \\
\hline
\end{tabular}

${ }^{a}$ Mann-Whitney $U$-nonparametric testing $(P<0.05$ indicates significance).

${ }^{b}$ Fishers exact test.
For multivariate analysis to compare baseline variables (thyroid volume, age, ${ }^{131}$ I uptake, effective half-life) and thyroid status, we used logistic regression analysis. The coefficients of the independent variables in the regression were transformed to give the odds of a particular treatment outcome. The odds ratios (ORs) are expressed with $95 \%$ CIs. The regression was repeated at 3, 5 and 10 years with $P$ value less than 0.05 taken as indicating statistical significance in all tests. All $P$ values presented are two tailed.

\section{Results \\ Baseline measurements}

Baseline characteristics are shown in Tables 2 and 3. In comparison with patients with typical Graves' disease, those with Graves' in a nodular goitre were more likely to be male, older and to require more activity to achieve the target $60 \mathrm{~Gy}$ absorbed dose. The maximum uptake of ${ }^{131} \mathrm{I}$ after tracer and therapy administrations was reduced in nodular glands although the ${ }^{131}$ I effective half-life was slightly but not significantly longer. Only five patients required $400 \mathrm{MBq}$ or more to deliver a target absorbed dose of $60 \mathrm{~Gy}$. The maximum thyroidal ${ }^{131} \mathrm{I}$ uptake was very similar for the tracer and therapy (Table 3 ). The median thyroid volume was greater in the group with nodules. Five patients requiring over $400 \mathrm{MBq}$ had significantly larger thyroid volumes (mean: $56.4 \mathrm{ml}$; range: $37.9-96.8 \mathrm{ml} ; P<0.05$ ). Median effective half-life in Graves' and Graves' with nodules was not found to be statistically significant. Analysis of the whole patient cohort gave a median absorbed thyroid dose of $55.8 \mathrm{~Gy}$ (55.03-58.03).

\section{Treatment outcomes}

Clinical outcomes for patients with typical Graves' disease $(n=227)$ and Graves' in a nodular thyroid $(n=57)$ are shown in Fig. 1. At 18 months, $44.2 \%$ of all study patients were euthyroid on no specific therapy, $9.0 \%$ were on replacement L-thyroxine, $11.6 \%$ were still taking antithyroid medication and $35.2 \%$ had required a second administration of ${ }^{131} \mathrm{I}$ (fixed dose of $75 \mathrm{MBq}$ ) because of persistent hyperthyroidism requiring antithyroid medication.

The proportion of patients requiring further radioiodine increased to $43.8 \%$ by 3 years but thereafter changed little $(47.0 \%$ at 5 years, $48.6 \%$ at 10 years). No serious adverse effects of radioiodine (post-therapy flare of hyperthyroidism or significant exacerbation of thyroid eye disease) were observed. At 3, 5 and 10 years after administration, $41.4,37.7$ and $30.0 \%$, respectively of patients were euthyroid on no thyroid medication. The proportion of patients becoming hypothyroid increased from $12.9 \%$ at 3 years to $17.0 \%$ at 5 years and $21.4 \%$ at 10 years. After 3 years, a small percentage of patients were still on antithyroid medication usually because further ${ }^{131} \mathrm{I}$ therapy was contraindicated. By 5 years no patients remained on antithyroid drugs. 
Table 3 Metrics for calculating a fixed target absorbed dose of 60 Gy to the thyroid

\begin{tabular}{|c|c|c|c|c|c|}
\hline & $\begin{array}{c}\mathrm{Na}^{131} \text { I activity } \\
\text { [median (range)] (MBq) }\end{array}$ & $\begin{array}{l}\text { Thyroid volume } \\
\text { [median (range)] (ml) }\end{array}$ & $\begin{array}{c}\text { Effective half-life } \\
\text { [median (range)] (days) }\end{array}$ & $\begin{array}{c}\text { Diagnostic uptake } \\
\text { [mean (range)] (\%) }\end{array}$ & $\begin{array}{l}\text { Therapeutic uptake } \\
\text { [mean (range)] (\%) }\end{array}$ \\
\hline Graves & $76(17.4-400)$ & $16.9(3.1-52.4)$ & $5.18(1.15-8)$ & $60.27(14.8-95.9)$ & $57.1(18.5-96)$ \\
\hline Graves + nodules & $99(33-1377)$ & $20.2(4.5-96.8)$ & $5.45(1.35-8)$ & $53.6(23.2-85.4)$ & $50.5(19.9-82.1)$ \\
\hline All & $17.4-1377$ & $3.1-96.8$ & $1.15-8$ & $14.8-95.9$ & $18.5-96$ \\
\hline$P$ value & $0.0309^{\mathrm{a}}$ & $0.0381^{\mathrm{b}}$ & $0.3589^{\mathrm{a}}$ & $0.0019^{b}$ & $0.0020^{\mathrm{b}}$ \\
\hline
\end{tabular}

${ }^{a}$ Mann-Whitney $U$-nonparametric testing $(P<0.05$ indicates significance).

bUnpaired two-tailed $t$-test $(P<0.05$ indicates significance).

Fig. 1

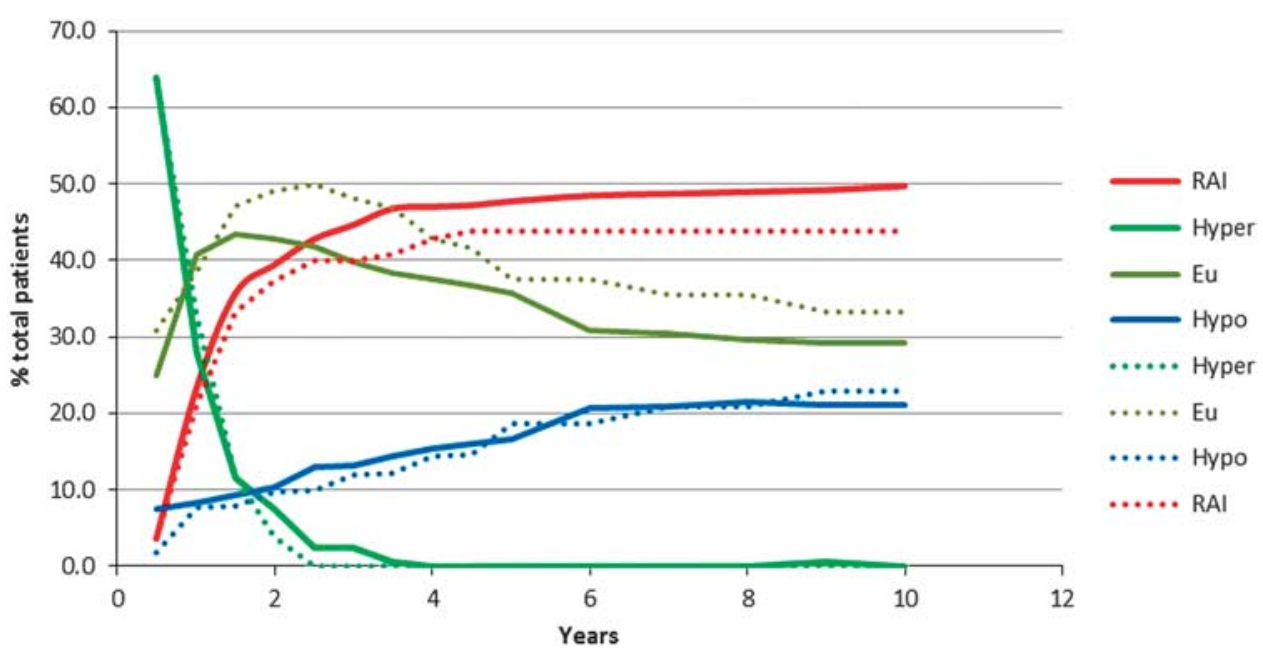

Treatment outcomes for patients with Graves' disease $(n=227)$ (solid lines) and for Graves with nodules ( $n=57)$ (dotted lines). EU, euthyroidism; hypo, hypothyroidism; hyper, hyperthyroidism; RAl, radioactive iodine.

In comparison with patients with typical Graves' disease, those with Graves' in a nodular thyroid became nonhyperthyroid sooner and none required antithyroid medication by 3 years (Fig. 1). At 10 years, a slightly greater proportion were euthyroid (33.3 vs. 29.2\%) or hypothyroid (22.9 vs. $21.0 \%)$ and fewer had required a second administration of ${ }^{131} \mathrm{I}$ ( 43.8 vs. $\left.49.7 \%\right)$.

\section{Factors affecting treatment outcomes Thyroid volume}

From multivariate analysis, increasing thyroid volume was found to be highly significant in the likelihood of a patient responding to a single administration of ${ }^{131} \mathrm{I}$. The ORs (95\% CIs) for achieving a nonhyperthyroid state (euthyroidism or hypothyroidism on L-thyroxine) are shown in Table 4 . At 3 years, OR was $1.044(1.014-1.077, P=0.005)$, at 5 years the OR had decreased to $1.04(1.011-1.074, P=0.008)$ and at 10 years to $1.032(1.004-1.063, P=0.029)$. Thyroid volume did not correlate with effective ${ }^{131}$ I half-life or maximum percentage ${ }^{131}$ I uptake.

\section{Age at treatment}

Increasing age at the point of treatment was significantly associated with the likelihood of a patient successfully responding to a single administration (Fig. 2). The corresponding ORs at 3, 5 and 10 years were very similar at $0.976(0.955-0.997), 0.97$ and 0.969 .

\section{Effective iodine-131 half-life and maximum iodine-131 uptake}

Neither effective half-life nor maximum ${ }^{131}$ I uptake were significantly associated with the need for further ${ }^{131} \mathrm{I}$ treatment.

\section{Duration of antithyroid treatment}

We found no significant association between length of antithyroid treatment before ${ }^{131} \mathrm{I}$ treatment and treatment outcomes.

\section{Discussion}

The results of this study indicated that a targeted $60 \mathrm{~Gy}$ absorbed dose to the thyroid can delay the onset of hypothyroidism in about a quarter of patients with Graves' disease. Using the protocol adopted in this study, $62 \%$ of patients were treated once with a mean ${ }^{131} \mathrm{I}$ activity of $106 \mathrm{MBq}$. The remainder required a second ${ }^{131}$ I administration usually within 2 years. In patients receiving a single administration, euthyroidism persisted 
Table 4 Odds ratios at 3, 5 and 10 years for achieving a euthyroid state

\begin{tabular}{|c|c|c|c|c|c|c|}
\hline & \multicolumn{2}{|c|}{ Thyroid volume (ml) } & \multicolumn{2}{|c|}{ Age at treatment (years) } & \multicolumn{2}{|c|}{ Effective half-life of iodine-131 (days) } \\
\hline & OR $(95 \% \mathrm{Cl})$ & $P$ value & OR $(95 \% \mathrm{Cl})$ & $P$ value & OR (95\% Cl) & $P$ value \\
\hline 3 years & $1.04(1.01-1.07)$ & 0.005 & $0.97(0.95-0.99)$ & 0.030 & $1.00(0.81-1.23)$ & 0.994 \\
\hline 5 years & $1.04(1.01-1.07)$ & 0.008 & $0.97(0.95-0.99)$ & 0.007 & $1.04(0.84-1.28)$ & 0.746 \\
\hline 10 years & $1.03(1.00-1.06)$ & 0.029 & $0.97(0.95-0.99)$ & 0.007 & $1.04(0.85-1.29)$ & 0.677 \\
\hline
\end{tabular}

$\mathrm{Cl}$, confidence interval; OR, odds ratio.

Fig. 2

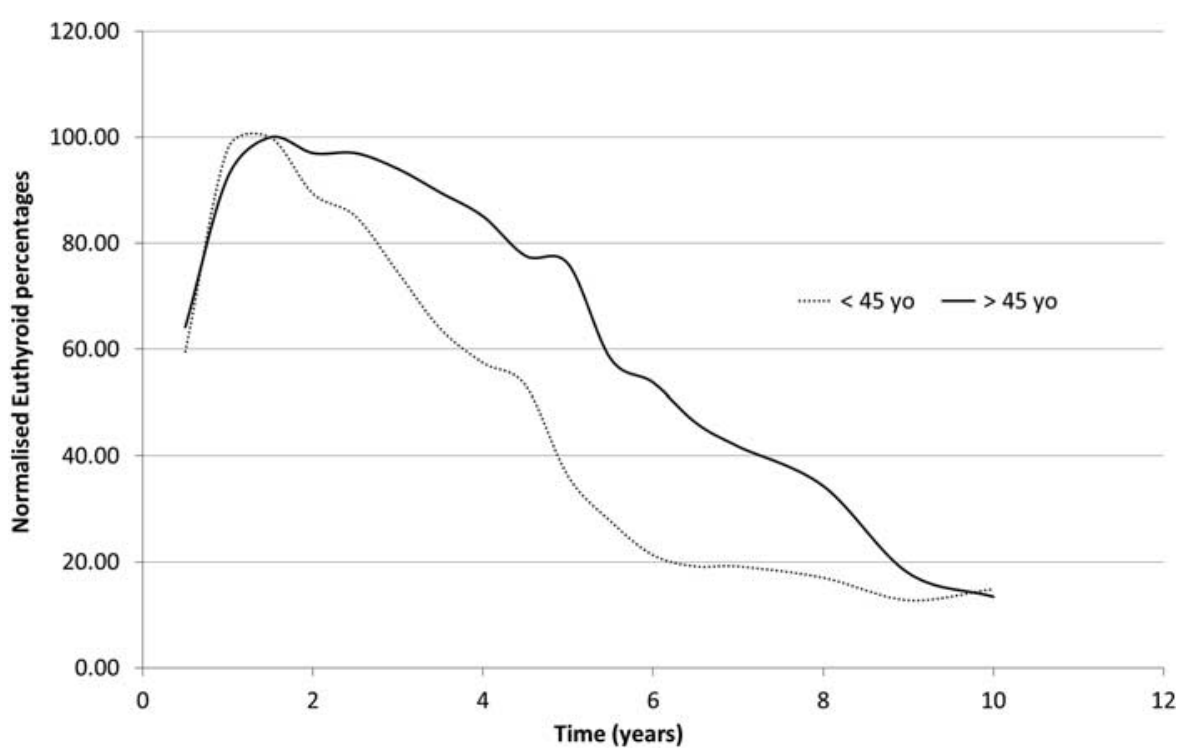

Radiation response to 60 Gy for the euthyroid group on the basis of age at administration.

for 10 years and might be expected to continue for an average of 15 years [11]. This approach was associated with continued requirement for oral antithyroid therapy in about a quarter of patients for 18 months. It should be noted that none became overtly hyperthyroid. Importantly, we excluded patients with cardiac complications in whom hyperthyroidism needed to be corrected more rapidly.

An absorbed thyroid dose of $60 \mathrm{~Gy}$ was chosen for this study after a previous study at this centre demonstrated a high rate of treatment failure at 12 months with lower absorbed doses [9]. Howarth et al. [12] in a study of patients with Graves' disease comparing 60 and $90 \mathrm{~Gy}$ absorbed doses to the thyroid reported $46 \%$ of patients were euthyroid on no specific medication with a median follow-up of 37.5 months. The authors concluded that $60 \mathrm{~Gy}$ was a better option than $90 \mathrm{~Gy}$ where the aim of treatment was to achieve euthyroidism and to delay the onset of hypothyroidism for as long as possible.

The difference between intended and therapeutically achieved target absorbed doses in Graves' disease varies widely in previous publications. The coefficient of variation of $22.8 \%$ in this study compares well with previous reports of $18-28 \%[13,14]$ and is considerably lower than others [15]. We noted a significant correlation between pretherapy thyroid volume (and hence thyroid mass) and treatment outcome and this may be relevant when comparing our results with other studies; Thyroid mass $(>26 \mathrm{~g})$ has previously been shown to be an important predictor of inadequate response to ${ }^{131} \mathrm{I}$ therapy for patients treated with $60-90$ Gy $[12,13]$. The relatively small mean thyroid volume $(18 \mathrm{ml})$ in this study is likely to be an important factor in determining the successful outcome of our patients.

Reliance on single measurements of ${ }^{131} \mathrm{I}$ uptake at $24 \mathrm{~h}$ to determine activity is potentially inaccurate because of the variability of the biological half-life of ${ }^{131}$ I $[16,17]$. Maximum ${ }^{131}$ I uptake occurs after $24 \mathrm{~h}$ in $54 \%$ of patients with Graves' disease [18]. This may be important in interpretation of the results of previous studies comparing individualized and fixed activity approaches $[5,19,20]$. In our study, ${ }^{131}$ I uptake was measured over 6 days and there was good correlation between diagnostic and therapeutic maximum uptake values. A wide variation in ${ }^{131} \mathrm{I}$ effective half-life was noted in this study although the 
mean of 5.3 days compares well with previous reports $[12,13]$.

A shorter ${ }^{131}$ I effective half-life was found to be associated with an increased risk of hypothyroidism at 3 years in keeping with previous reports [21] although we did not find an association with maximum fractional ${ }^{131}$ I uptake. There may be a need to increase the target absorbed dose in cases where the effective half-life as determined from the tracer administration is found to be short.

Older patients in our study were more likely to become euthyroid after a single administration of ${ }^{131} \mathrm{I}$ possibly indicating less severe hyperthyroidism at the outset. Pretreatment with propylthiouracil but not carbimazole may influence treatment outcomes after ${ }^{131}$ I therapy [22]. However the use of this drug in our patients was limited to a small number of all ages who developed skin reactions to carbimazole.

The presence of nodules on ultrasonography in Graves' patients may be an additional confounding factor in the comparison of outcomes from different studies. Patients with autonomous thyroid nodules or toxic adenomas were excluded from our study as with a number of other previously reported studies [12,20]. Patients with nodular disease have conventionally been considered to be more radioresistant in comparison to those with typical Graves' disease [23] although at least one study has noted that these patients may have better long-term results after a single administration of ${ }^{131}$ I therapy [24]. Our data suggest that patients with Graves' in a nodular thyroid have a good response to ${ }^{131} \mathrm{I}$ therapy.

There have been few prospective randomized-controlled trials comparing individualized dosimetry versus fixed activity approaches $[5,20,25]$. In an open randomized 12-month trial comparing three fixed ${ }^{131}$ I activities with an individualized absorbed dose equivalent to $70 \mathrm{~Gy}$ [20], $50 \%$ of patients treated by the individualized dose were euthyroid, $41 \%$ still required antithyroid treatment and 9\% were hypothyroid. Results for the fixed activity approach were similar. No long-term data was presented. In another randomized trial, 98 patients with Graves' disease received a fixed activity of $555 \mathrm{MBq}$ and were compared by outcome at 6 months to 107 patients who were administered a planned absorbed dose of $100 \mathrm{~Gy}$ [25]. A successful outcome, defined as elimination of hyperthyroidism, occurred in $71 \%$ of those receiving fixed activity versus $58 \%$ in the calculated absorbed dose group. This difference did not quite achieve significance. Long-term outcomes were not reported. Leslie et al. [5] randomized 88 patients with Graves' disease to either (i) $235 \mathrm{MBq}$; (ii) $350 \mathrm{MBq}$; (iii) $2.96 \mathrm{MBq} / \mathrm{g}$ thyroid ( $60 \mathrm{~Gy}$ ) or (iv) $4.44 \mathrm{MBq} / \mathrm{g}$ thyroid $(\sim 100 \mathrm{~Gy})$. With a mean follow-up of 63 months, the investigators reported no significant differences in clinical outcomes. This study was considerably underpowered and clinically important differences between groups may have been missed.
Irrespective of whether the objective of ${ }^{131}$ I therapy is the elimination of hyperthyroidism or the maintenance of euthyroidism for as long as possible, the principle of ensuring that radiation doses as low as reasonably achievable (ALARA) should be applied [7,26]. This principle is not always respected in the treatment of thyroid disease [11]. In our study, a very wide range of activity (mean: $106 \mathrm{MBq}$; range $17.4-1377 \mathrm{MBq}$ ) was associated with a targeted absorbed dose of $60 \mathrm{~Gy}$ reflecting the poor correlation between administered activity and the absorbed dose. Only five of our patients required the Royal College of Physicians recommended fixed activity of $400 \mathrm{MBq}$. Even a fixed activity of $370 \mathrm{MBq}$ may result in some two-thirds of patients being unnecessarily over-irradiated $[4,11]$.

It is acknowledged that a dosimetric approach entails more visits to hospital with associated costs and the increased risk of recurrent hyperthyroidism in comparison with a fixed ablative dose. In patients with cardiovascular disease this could have serious consequences, and hence significant cardiac disease is, in our view, a contraindication to this approach. Furthermore, if patients are lost to follow-up, there is the potential for untreated hypothyroidism but this is also the case for patients receiving fixed doses.

The strengths of this study include: (i) a wellcharacterized cohort of patients all treated in one centre using a standard protocol, in whom cardiac disease was excluded and in whom the presence of thyroid nodules was taken into account in the analysis; (ii) achievement of the targeted absorbed dose of $60 \mathrm{~Gy}$ with an acceptable coefficient of variation; (iii) prolonged follow-up with results at 10 years and (iv) outcome measurement of euthyroidism requiring no specific therapy as the preferred measure of successful treatment. A limitation of the study is that we did not directly compare outcomes with patients treated with fixed ${ }^{131}$ I activities in a randomized-controlled trial design.

On the basis of our results, a dosimetric approach would have resulted in nearly two-thirds of patients receiving an average of three to five times less radioiodine compared with standard fixed radiation activities of $370-550 \mathrm{MBq}$. Further research is needed to identify the optimal absorbed dose for different patient cohorts and investigate which patients would benefit most from this approach.

\section{Acknowledgements}

The authors acknowledge the invaluable help provided by our specialist nurses.

This work was supported by the NIHR Clinical Research Network.

\section{Conflicts of interest}

There are no conflicts of interest. 


\section{References}

1 Ross DS, Birch HB, Cooper DS, Greenlee MC, Laurberg P, Maia AL, et al. 2016 American Thyroid Association GUIDELINES for diagnosis and management of hyperthyroidism and other causes of thyrotoxicosis. Thyroid 2016; 26:1343-1421.

2 Royal College of Physicians. Radioiodine in the management of benign thyroid disease Clinical guidelines Report of a working party. London, UK: RCP; 2007.

3 Stokkel MP, Handkiewicz Junak D, Lassmann M, Dietlein M, Luster M. EANM procedure guidelines for therapy of benign thyroid disease. Eur J Nucl Med Mol Imaging 2010; 37:2218-2228.

4 Allahabaida A, Daykin J, Sheppard M, Gough SC, Franklyn JA. Radioiodine treatment of hyperthyroidism-prognostic factors for outcome. J Clin Endocrinol Metab 2001; 86:3611-3617.

5 Leslie WD, Ward L, Salamon EA, Ludwig S, Rowe RC, Cowden EA. A randomised comparison of radioiodine doses in Graves' hyperthyroidism. J Clin Endocrinol Metab 2003; 88:978-983.

6 Metso $S$, Jaatinen $P$, Huhtala $H$, Luukkaala T, Oksala H, Salmi J. Long term follow-up study of radioiodine treatment of hyperthyroidism. Clin Endocrinol (Oxf) 2004; 61:641-648

7 European Union. European Council Directive 2013/59 Euratom on basic safety standards for the protection against the dangers arising from the exposure to ionising radiation and repealing directives 89/618/Euratom, 90/641/Euratom, 96/29/Euratom, 97/43/ Euratom and 2003/122/Euratom. OJEU 2014; 57:1-73

8 Canaris GJ, Manowitz NR, Mayor G, Ridgway EC. The Colorado thyroid disease prevalence study. Arch Intern Med 2000; 160:526-534.

9 Flower MA, Al-Saadi A, Harmer CL, McCready R, Ott RJ. Dose-response study on thyrotoxic patients undergoing positron emission tomography and radioiodine therapy. Eur J Nucl Med 1994; 21:531-536.

10 Crawford DC, Flower MA, Pratt BE, Hill C, Zweit J, McCready, R, Harmer CL. Thyroid volume measurement in thyrotoxic patients: comparison between ultrasonography and iodine-124 positron emission tomography. Eur J Nucl Med 1997; 24:1470-1478.

11 Van Isselt JW, de Klerk JMH, Lips CJM. Radioiodine treatment of hyperthyroidism: fixed or calculated doses; intelligent design or science. Eur J Nucl Med Mol Imaging 2007; 34:1883-1884.

12 Howarth D, Epstein M, Lan L, Tan P, Booker J. Determination of the optimal minimum radioiodine dose in patients with Graves' disease: a clinical outcome study. Eur J Nucl Med 2001; 28:1489-1495.

13 Reinhardt MJ, Brink I, Joe AY, von Mallek D, Ezziddin S, Palmedo H, Krause TM. Radioiodine therapy in Graves' disease based on tissue absorbed dose calculations: effect of pre-treatment thyroid volume on clinical outcome. Eur J Nucl Med 2002; 29:1118-1124.

14 Bockisch A, Jamitzky T, Derwanz R, Biersack HJ. Optimised dose planning of radioiodine therapy of benign thyroidal diseases. J Nucl Med 1993; 34:1632-1638

15 Catargi B, Leprat F, Guyot M, Valli N, Dominique Ducassou D, Tabarin A Optimized radioiodine therapy of Graves' disease: analysis of the delivered dose and of other possible factors affecting outcome. Eur J Endocrinol 1999; 141:117-121.

16 Kaplan MM, Meier DA, Dworkin JJ. Treatment of hyperthyroidism with radioactive iodine. Endocrinol Metab Clin North Am 1998; 27:205-223.

17 Van Isselt JW, Broekhuizen-de Gast HS. The radioiodine turnover rate as a determinant of radioiodine treatment outcome in Graves' disease. Hell J NuCl Med 2010; 13:2-5.

18 Vemulakonda US, Atkins FB, Ziessman HA. Therapy dose calculation in Graves' disease using early $\mathrm{I}-123$ uptake measurements. Clin Nucl Med 1996; 21:102-105

19 De Rooij A, Vandenbroucke JP, Smit JWA, Stokkel MPM, Dekkers OM Clinical outcomes after estimated versus calculated activity of radioiodine for the treatment of hyperthyroidism: systematic review and meta-analysis. Eu J Endocrinol 2009; 161:771-777.

20 Jarlov VAE, Hegedus L, Kristensen LO, Nygaard B, Hansen JM. Is calculation of the dose in radioiodine therapy of hyperthyroidism worthwhile? Clin Endocrinol (Oxf) 1995; 431:325-329.

21 Krohn T, Hanscheid H, Muller B, Behrendt FF, Heinzel A, Mottaghy FM, Verburg FA. Maximum dose rate is a determinant of hypothyroidism after ${ }^{131} \mathrm{I}$ therapy of Graves' disease but the total thyroid absorption dose is not. J Clin Endocrinol Metab 2014; 99:4109-4115.

22 Weetman AP. Radioiodine treatment for benign thyroid diseases. Clin Endocrinol (Oxf) 2007; 66:757-764.

23 Farrar JJ, Toft AD. lodine-131 treatment of hyperthyroidism: current issues. Clin Endocrinol (Oxf) 1991; 35:207-212.

24 Delgrange E, Weber E, Michel L, deCoster P, Buysschaert M, Donckier J. Status of three years of hyperthyroidism treatment with iodine 131. Acta Clin Belg 1994; 49:200-2007.

25 Peters H, Fischer C, Bogner U, Reiners C, Schleusener H. Radioiodine therapy of Graves' hyperthyroidism: standard vs calculated 131 iodine activity. Results from a prospective, randomised, multicentre study. Eur J Clin Invest 1995; 25:186-193.

26 Buscombe J, Hirji H, Witney-Smith C. Nuclear medicine in the management of thyroid disease. Expert Rev Anticancer Ther 2008; 8:1425-1431. 